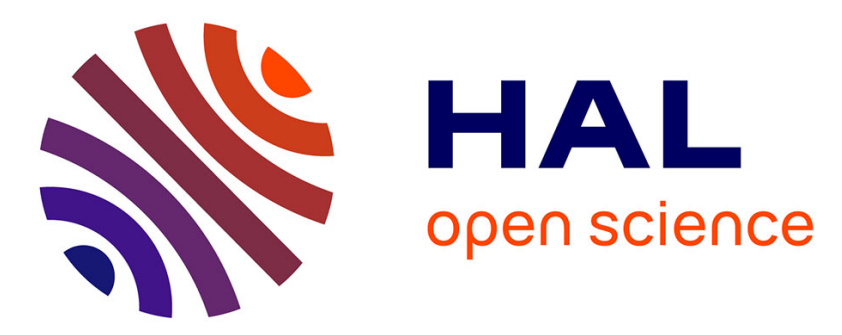

\title{
An Environmental Stress Cracking (ESC) test to study the ageing of biopolymers and biocomposites
}

\author{
N. Pons, Anne Bergeret, J. -C. Benezet, Laurent Ferry, F. Fesquet
}

\section{To cite this version:}

N. Pons, Anne Bergeret, J. -C. Benezet, Laurent Ferry, F. Fesquet. An Environmental Stress Cracking (ESC) test to study the ageing of biopolymers and biocomposites. Polymer Testing, 2011, 30 (3), pp.310-317. 10.1016/j.polymertesting.2010.11.015 . hal-02949491

\section{HAL Id: hal-02949491 \\ https://hal.science/hal-02949491}

Submitted on 10 Dec 2020

HAL is a multi-disciplinary open access archive for the deposit and dissemination of scientific research documents, whether they are published or not. The documents may come from teaching and research institutions in France or abroad, or from public or private research centers.
L'archive ouverte pluridisciplinaire HAL, est destinée au dépôt et à la diffusion de documents scientifiques de niveau recherche, publiés ou non, émanant des établissements d'enseignement et de recherche français ou étrangers, des laboratoires publics ou privés. 


\title{
An Environmental Stress Cracking (ESC) test to study the ageing of biopolymers and biocomposites
}

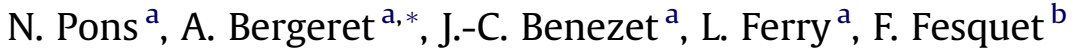 \\ a Ecole des Mines d'Alès, Centre des Matériaux de Grande Diffusion, 6 avenue de Clavières, 30319 Alès, France \\ ${ }^{\mathrm{b}}$ Université de Montpellier II, IUT Science et Génie des Matériaux, 8 rue Jules Raimu, 30907 Nîmes, France
}

\begin{abstract}
A B S T R A C T
An Environmental Stress Cracking test was used to investigate damage to glass fiber reinforced poly(lactic acid) based biocomposites. The study was performed in water. The main advantages were a significant decrease in experiment duration compared to natural, artificial or accelerated tests and an increase in the reliability of the results. Depending on the specific nature of the glass fiber used, significant types of failure behavior were observed.
\end{abstract}

Keywords:

Biocomposite

Glass fiber

Sizing

Ageing

Environmental stress cracking

\section{Introduction}

Glass-fiber reinforced composites are widely used in industry (e.g. the automobile industry) as structural materials. Under their conditions of use, these materials are subject to ageing, with the ageing phenomena conditioned by the environment. In the case of composites, the ageing process is reflected by different types of degradation. In certain specific environments this degradation is critical, while in other climates no effect is observed.

The development of biocomposites is expanding rapidly, with most materials based on a poly(lactic acid) (or PLA) matrix. Some applications of PLA require knowledge about the durability and predictability of the material's properties. The rate of PLA hydrolysis increases markedly above $\mathrm{Tg}$ [1] and also as hydrolysis proceeds, presumably due to the production of hydrophilic groups (alcohol, acid...) [2]. Likewise, hydrophilic molecules and functional groups such as lactide and carboxylic groups, whose concentrations are proportional to degradation, increase the level of moisture. In addition, the

\footnotetext{
* Corresponding author. Tel.: +33 4667853 44; fax: +33 466785365 . E-mail address: Anne.Bergeret@ema.fr (A. Bergeret).
}

morphology - both crystallinity and the presence of microvoids or porosity - may affect water permeation [3].

A series of tests has been developed to characterize the evolution of material properties. These tests are intended to simulate the ageing of materials in use. Singh [4] summarizes the various mechanisms of plastic degradation and the methods used to observe them.

In environmental ageing tests, samples are placed in natural conditions (temperature, humidity, light exposure...). After a period of up to several months, the samples are characterized by visual observation (crack formation, chalking, color changes...) and analytical methods (IR, mechanical tests...) [4]. However, these tests have major drawbacks. Firstly, they require long ageing periods and, in addition, they are representative of a specific location, i.e. the study site. For example, the same material will obviously not age in the same way in a tropical region as in a temperate climate $[5,6]$.

The second kind of test, the artificial ageing test, reproduces natural conditions in the laboratory. One or more specific parameters are controlled. The simplest example is temperature, which is controlled by air-conditioning. These tests help to accelerate ageing but can never fully simulate all the external conditions (sun exposure, microorganisms...). 
Finally, most of the tests currently used are accelerated ageing tests. Here, one or more environmental parameters are modified. Thus, for a hydrothermal ageing test, temperature and humidity are both increased, although UV-ageing does not occur (since the test is performed in an autoclave). Moreover, amplifying a given factor may cause parasitic phenomena that would not occur in normal conditions. Some chemical reactions involved in the failure of a material are sequential but most of them require the diffusion of reactants (themselves products of reactions). As a result, the various reactions do not accelerate in the same way as a function of temperature. Accelerated ageing tests may, therefore, lead to different failure mechanisms than those induced under natural conditions. Finally, in the environment the material may undergo mechanical stresses concurrently with environmental degradation.

Several papers [7-12] deal with the relationship between natural and artificial ageing processes and conclude that there is no correlation. This viewpoint is reflected in several standards [13,14]. Even accelerated ageing outdoors [4,14] using mirrors to increase sun exposure gave contradictory information concerning polyolefins [15]. Similar doubts have been expressed regarding the relationship between data obtained in an extreme environment and the prediction of performances in a temperate climate [6].

A phenomenon usually called Environmental Stress Cracking has been used to try to predict failure under stress. Two methods have been developed. The first involves tests where specimens are stressed under constant strain [16,17] or constant stress [18]. Time to crazing is measured by observation of the samples. The other type of test uses a slow strain rate $(10-3 \% / \mathrm{s}[19-22])$ or slow stress rate (4 MPa/h $[23,24])$. However, all of these tests are carried out in a chemical environment (acetone, ethanol and other organic solvents).

In order to determine the ageing mechanisms of a material in service, an accelerated ageing method was adapted by applying a slow strain rate. Our method is able to simulate the ageing of the material under stress in a well-defined environment. The method is rapid and easy to set up as well as representative of the ageing process.

Our test could yield similar results to other accelerated ageing tests without causing the emergence of secondary phenomena (crystallization...). The main phenomenon observed is environmental stress cracking, which is the susceptibility of the material to failure under the conditions of use [15]. Turnbull et al. [21] adopted a similar approach by comparing the results of four point bending, constantload and slow strain rate tests.

For this study, to demonstrate the efficiency of the ESC test adapted to our material, it will be compared to a classical three-point bending ( $3 \mathrm{~PB}$ ) test before and after ageing in water.

\section{Experimental}

\subsection{Materials and processing}

\subsubsection{Materials}

PLA (PLA 700D) was provided by Nature Works LLC (Blair, USA). The polymer has an average molecular weight
$\left(M_{n}\right)$ of $142 \mathrm{kDa}$ and a polydispersity index of 1.80 determined by SEC (THF, $25^{\circ} \mathrm{C}$ ).

Two different types of glass fibers (Diameter $=10 \mu \mathrm{m}$ ), a commercial E-glass and a new X-glass, were provided by OCV Reinforcement International (Chambéry, France). The composition of the X-glass fiber enabled relatively high solubility, especially of alkaline components. Both fibers were coated with a standard water-based sizing used in traditional composites such as PET or PBT/E-glass. The sizing mainly consists of an aminosilane coupling agent and an epoxy sticking agent. Tenacity, which is an indicator of the resistance of the sized fiber, was measured by a tensile test applied to a long fiber. The maximum force (in N) was divided by the weight of $1 \mathrm{~km}$ of fiber (in tex). Tests were performed by OCV Reinforcement in compliance with Standard ISO 3341. The X-glass and E-glass fiber tenacity were $0.4 \mathrm{~N} /$ tex and $0.45 \mathrm{~N} /$ tex respectively.

\subsubsection{Composite processing}

The pellets were dried at $50{ }^{\circ} \mathrm{C}$ under vacuum for $12 \mathrm{~h}$ before processing (manufacturer's recommendation). The composites consisted of a PLA matrix reinforced by $30 \%$ in mass of E-glass or X-glass fibers (respectively named PLA-E and PLA-X). The fiber content was verified by LOI $(1 \mathrm{~h}$, $\left.600{ }^{\circ} \mathrm{C}\right)$.

A co-rotating twin-screw extruder (Clextral BC21) was used for melt blending. Temperature was set to $170{ }^{\circ} \mathrm{C}$ and the screw rotation speed was maintained at $250 \mathrm{rpm}$. After extrusion, the composites were cooled in a water bath and pelletized.

The composite pellets were dried under vacuum at $50{ }^{\circ} \mathrm{C}$ for $12 \mathrm{~h}$ and were then injection-molded at $170{ }^{\circ} \mathrm{C}$ (Sandretto, 95 tons) to obtain tensile samples compliant with Standard ISO 527-2 type 1A. The screw speed during the plasticization step was maintained at $30 \mathrm{rpm}$, cycles were $67 \mathrm{~s}$ long and the mold temperature was set at $40^{\circ} \mathrm{C}$.

\subsubsection{Glass fiber length}

The initial glass fiber length was $4.5 \mathrm{~mm}$. The fiber length after processing was measured as follows. First, the composites were dissolved in THF. Then, the solutions were placed on glass lamella under vacuum and observed using an optical microscope. Finally, the images were processed by means of a software application developed by the laboratory. Approximately one thousand fibers were measured and the average size in number $\left(T_{n}\right)$ and length $\left(T_{l}\right)$ were calculated. The dispersity factor $\left(D_{f}\right)$ was determined using the following equation (Equation 1):

$D_{f}=\frac{T_{1}-T_{n}}{T_{n}}$

\subsection{Mechanical properties: three-point bending test}

Three-point bending ( $3 \mathrm{~PB}$ ) tests were carried out at least 3 days after injection molding at ambient temperature and humidity. In order to determine the flexural modulus and the stress and deformation at break, the size of the samples used was $80 \mathrm{~mm} \times 10 \mathrm{~mm} \times 4 \mathrm{~mm}$. Specimens were loaded with a crosshead speed of $2 \mathrm{~mm} / \mathrm{min}$, using a Zwick Z100 testing machine equipped with a $2.5 \mathrm{kN}$ load 
cell (Zwick/Roell, $2 \mathrm{mV} / \mathrm{V}$ ) and the span was set at $64 \mathrm{~mm}$ (Standard ISO 178). Five specimens were tested at $23^{\circ} \mathrm{C}$ and $50 \%$ R.H. The stress, deformation and modulus were calculated using Equation 2, Equation 3 and Equation 4 respectively.

$$
\begin{aligned}
& \sigma(M P a)=\frac{3 \times F \times L}{2 \times b \times h^{2}} \\
& \varepsilon(\%)=\frac{6 \times \delta \times h}{L} \\
& E(G P a)=\frac{F \times L^{3}}{4 \times b \times h \times \delta}
\end{aligned}
$$

\subsection{Immersion ageing}

\subsubsection{Water uptake}

The water uptake was measured by weighing the samples after ageing (one week, $23{ }^{\circ} \mathrm{C}$, deionized water). For the ESC immersion test, water was removed and the samples were quickly wiped and weighed (Mettler balance, accuracy $\pm 0.1 \mathrm{mg}$ ) to assess the mass variation. The water content $\mathrm{M}_{\mathrm{t}}$ was calculated as follows (Equation 5).

$M_{t}(\%)=\frac{W_{t} W_{o}}{W_{o}} \times 100$

$W_{0}$ and $W_{t}$ were the specimen weights before and after ageing respectively. For the composites, the water uptake due to the matrix fraction ( $70 \%$ in mass) was subtracted from the total water uptake. The difference can be attributed to the influences of sizing and fibers.

\subsubsection{Environmental accelerated creep test}

The apparatus (length $=1558 \mathrm{~mm}$, width $=520 \mathrm{~mm}$ and height $=945 \mathrm{~mm}$ ) consisted of a frame and two arms on which were set the three-point bending supports. The arms were designed for a maximum traction/compression force of $100 \mathrm{kN}$. The force was measured with a $1 \mathrm{kN}$ form HBM load cell, model U3 (precision $0.2 \%$ ). A bath could be placed on the bench in order to immerse the specimen in a defined environment (air, water, enzyme solution etc.) at different temperatures (Fig. 1).

For this study, two environments were selected: air and water ( $8 \mathrm{~L}$ of de-ionized water) at room temperature $\left(23^{\circ} \mathrm{C}\right.$, measured using a J type sensor, precision $\left.+/-1{ }^{\circ} \mathrm{C}\right)$. Tests were carried out with a maximum deflection of $4.5 \%$ $(12 \mathrm{~mm})$. Three specimens of ESC material were tested.

Displacement was monitored using an incremental encoder (precision $<0.7 \%$ ). The selected strain rate was $0.5 \mathrm{~mm} / \mathrm{h}(0.1875 \% / \mathrm{h})$. This rate is an interesting factor because it provides results about ageing in $24 \mathrm{~h}$.

\subsection{Thermal analysis}

The crystallinity ratio was studied by Differential Scanning Calorimetry (DSC). The analyses were carried out using a Perkin Elmer PYRIS Diamond DSC equipped with a cooling attachment, under a nitrogen atmosphere. Data were

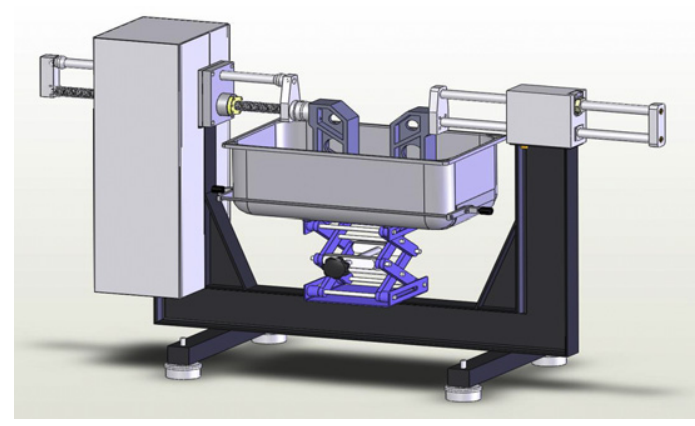

Fig. 1. ESC apparatus.

collected by heating the materials from $20{ }^{\circ} \mathrm{C}$ to $180{ }^{\circ} \mathrm{C}$ at a constant rate of $10^{\circ} \mathrm{C} / \mathrm{min}$. A PLA sample weight between 5 and $10 \mathrm{mg}$ was used sealed in aluminum pans. The melting temperature was measured and the crystallinity ratio was determined with the melting enthalpy measured for the ESC sample. Three analyses were carried out.

The crystallinity content $\left(\mathrm{x}_{\mathrm{c}}\right)$ was calculated from Equation (6) excluding the fiber content of the composites:

$x_{C P L A}(\%)=\frac{100 \cdot \Delta H_{m}}{93}$

where $\Delta \mathrm{H}_{\mathrm{m}}(\mathrm{J} / \mathrm{g})$ is the measured polymer melting enthalpy. A melting enthalpy of $93 \mathrm{~J} / \mathrm{g}$ has been reported by Fischer et al [25] for 100\% crystalline PLA.

For the composites, a similar Equation (7) was used, taking into account the PLA fraction (70\% in mass):

$x_{\text {cComposites }}(\%)=\frac{100 . \Delta 0_{m}}{93} \times 0.7$

The fusion enthalpy was calculated by subtracting the crystallization enthalpy $\left(\Delta H_{c}\right)$ from the melting enthalpy $\left(\Delta H_{f}\right)$ using Equation 8.

$\Delta H_{m}=\Delta H_{f}-\Delta H_{c}$

\subsection{Environmental scanning electron microscopy}

The surface morphology of fractured samples was observed by environmental scanning electron microscopy (ESEM) at room temperature. A Quanta 200 FEG (FEI Company) environmental scanning electron microscope was used to collect ESEM images for the composite specimens. A gold coating was deposed on the broken surface to protect the PLA surface. Samples were viewed perpendicular to the fracture surface. The aim was to observe the interface adhesion between the matrix and the fiber, the fracture mode and the fiber length after fracture. A magnification of 750 was used to observe the fiber surface.

\section{Comparison between ESC test and 3 PB test}

\subsection{Reproducibility of ESC test}

The reproducibility of the ESC test was clearly demonstrated by the low standard deviation (Table 1 and Fig. 2). 
Table 1

Results of PLA tested with ESC apparatus.

\begin{tabular}{llllll}
\hline & Sample 1 & Sample 2 & Sample3 & Average & $\begin{array}{l}\text { Standard } \\
\text { deviation }\end{array}$ \\
\hline Modulus & 3.15 & 3.15 & 3.32 & 3.20 & 0.53 \\
$\begin{array}{c}\text { Maximum } \\
\text { force }\end{array}$ & 116 & 117 & 118 & 117 & 1 \\
\hline
\end{tabular}

\subsection{Before water ageing}

Air was considered as a non-aggressive environment. Fig. 3 shows stress/strain curves (MPa/\%) for PLA and PLA composites obtained through ESC and 3 PB tests.

There were no significant differences between the ESC and 3 PB test curves of the pure PLA. No break was observed in either test.

The curves of the composites exhibited a higher maximum stress than that of the matrix. The modulus was higher with the ESC test than the 3 PB test. This result could be explained by a difference in apparatus geometry. The distance between the supports was $80 \mathrm{~mm}$ in the ESC test compared with $64 \mathrm{~mm}$ in the $3 \mathrm{~PB}$ test. In general, the displacement of macromolecules decreases when the strain rate is increased and the material appears to be stiffer [19].

Failure occurred later in the ESC test. This was due to matrix relaxation, enabling the polymer chains to move at low strain rate. The material became more ductile, leading to an increase in strain at break. These results are contrary to those obtained by Arnold [19].

The mechanical properties obtained by the ESC and 3 PB tests are given in Table 2 . The results obtained were similar. For the pure PLA, the modulus was approximately $3.3 \mathrm{GPa}$ and an increase of up to $10 \mathrm{GPa}$ was observed for the composites.

The maximum stress values displayed the same trends. It should be noted that the difference between the materials according to the ESC test was about $60 \mathrm{MPa}$, compared to $35 \mathrm{MPa}$ with the $3 \mathrm{~PB}$ test.

The difference in strain between the PLA-X and PLA-E composites was close to $0.25 \%$ for the $3 \mathrm{~PB}$ test and $0.65 \%$ for the ESC test.

Hence, ESC before ageing appears be an interesting test, able to highlight differences between the behavior of materials.

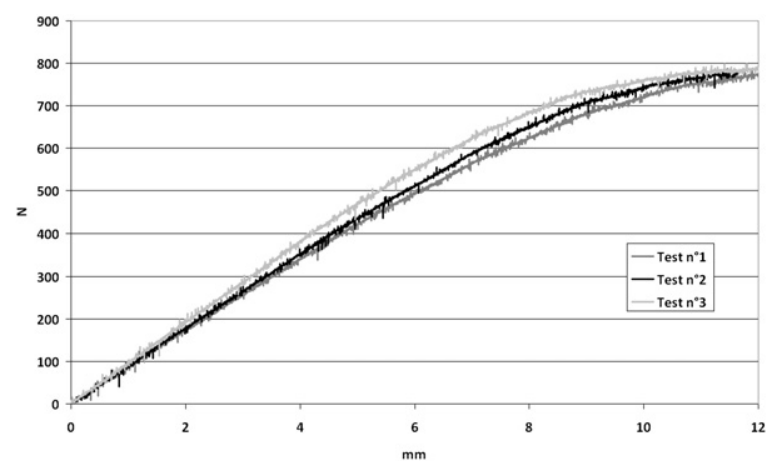

Fig. 2. Force/displacement curves for PLA before ageing.

\subsection{Water ageing}

\subsubsection{Water absorption}

The water uptake data (Table 3) show differences between the one day water immersion ESC test and a classical one week water immersion test. After one day (immersion test), pure PLA absorbed 0.22 wt\% of water whereas it absorbed $0.32 \mathrm{wt} \%$ of water during the one day water immersion ESC test. These results illustrate a marked increase $(+64 \%)$ in water diffusion within the PLA matrix, enhanced by the slow chain deformation occurring during the EAC test. Similar observations were made for the composites. However, it should be noted that specimen breakdown during the ESC test involved the emergence of two newly formed facture surfaces in contact with water. The area of these contact surfaces grew with time up to the global specimen section $\left(40 \mathrm{~mm}^{2}\right)$.

The contribution of the matrix to water absorption in the composites was evaluated. The experimental water uptake was less than the theoretical value whatever the composite $(0.21 \%$ for both composites compared to $0.15 \%$ and $0.20 \%$ for PLA-X and PLA-E respectively, for the one day immersion ESC test and $0.48 \%$ for both composites compared to $0.36 \%$ and $0.29 \%$ for PLA-X and PLA-E respectively, for the classical one week immersion test). The reduction in the water diffusion coefficient was caused by the fibers, which act as a barrier.

\subsubsection{Mechanical properties}

Fig. 4 shows the stress/strain (MPa/\%) curves for the PLA and PLA composites obtained by applying the ESC and 3 PB tests to water-aged materials.

As before ageing, the ESC and 3 PB tests curves for the pure PLA were similar (Table 4). No break was observed in the presence of water. Siparsky et al. [26] demonstrated that PLA hydrolysis at ambient temperature is a very slow diffusion mechanism compared, for example, to water vapor diffusion. The effect of matrix degradation by hydrolysis can, therefore, be considered negligible compared to the effect of matrix plasticization [27]. In the case of the composites, other phenomena appear simultaneously with the water uptake. Water molecules in the interphase would tend to have more influence on ageing behavior than in the bulk. The interphase area is the critical region of the composite. Previous studies have shown, for

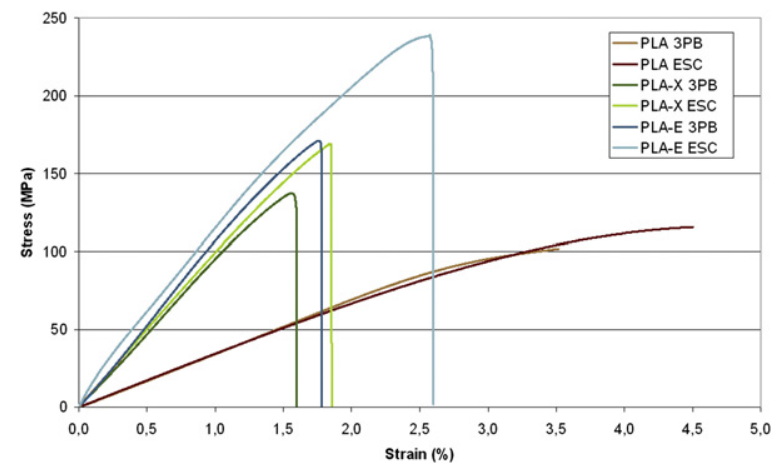

Fig. 3. Graphs of stress/strain for ESC and 3 PB tests in Air. 
Table 2

Comparison of mechanical properties obtained by ESC test and 3 PB test (Air).

\begin{tabular}{|c|c|c|c|c|c|c|}
\hline \multirow[t]{2}{*}{ Test material } & \multicolumn{3}{|l|}{ ESC test } & \multicolumn{3}{|l|}{3 PB Test } \\
\hline & Modulus (GPa) & Maximum stress (MPa) & Strain at break (\%) & Modulus (GPa) & Maximum stress (MPa) & Strain at break (\%) \\
\hline PLA & $3.20 \pm 0.53$ & $119 \pm 1$ & $>4.5$ & $3.36 \pm 0.02$ & $102 \pm 1$ & $3.48 \pm 0.02$ \\
\hline PLA-X & $10.03 \pm 0.11$ & $182 \pm 6$ & $1.89 \pm 0.11$ & $9.28 \pm 0.09$ & $138 \pm 4$ & $1.56 \pm 0.07$ \\
\hline PLA-E & $10.83 \pm 0.24$ & $241 \pm 2$ & $2.55 \pm 0.01$ & $10.15 \pm 0.25$ & $171 \pm 5$ & $1.82 \pm 0.11$ \\
\hline
\end{tabular}

Table 3

Experimental and theoretical water contents (wt\%) of samples after classical immersion test during one day (for PLA) and one week (for all materials) and after one day immersion ESC test.

\begin{tabular}{|c|c|c|c|c|c|c|}
\hline \multirow[t]{2}{*}{ Material } & \multicolumn{2}{|c|}{ One day immersion ESC test } & \multicolumn{2}{|c|}{ One day immersion test } & \multicolumn{2}{|c|}{ One week immersion test } \\
\hline & Experimental & Theoretical & Experimental & Theoretical & Experimental & Theoretical \\
\hline PLA & $0.32 \pm 0.03$ & $0.32 \pm 0.03$ & $0.22 \pm 0,07$ & $0.22 \pm 0,07$ & $0.68 \pm 0.09$ & $0.68 \pm 0.09$ \\
\hline PLA-X & $0.15 \pm 0.02$ & $0.21 \pm 0.02$ & ND & ND & $0.36 \pm 0.01$ & $0.48 \pm 0.06$ \\
\hline PLA-E & $0.20 \pm 0.02$ & $0.21 \pm 0.02$ & ND & ND & $0.29 \pm 0.00$ & $0.48 \pm 0.06$ \\
\hline
\end{tabular}

ND: not determined.

a PET/30 wt\% glass fiber composite [28,29], that global ageing results in matrix ageing (hydrolysis, crystallization) and interphase degradation (interfacial cracking, osmotic failure). The modulus was higher in the ESC test that the 3 PB test for the reasons described above.

Finally, the failure occurred at higher strains in the ESC test than the $3 \mathrm{~PB}$ test (as before ageing). It is interesting to note that different types of failure were observed in the different composites. The PLA-E composite tested by the ESC test broke down progressively, with a pronounced stress decrease near $1.8 \%$ strain, followed by a gradual stress decrease until $4.5 \%$ strain. In the case of the PLA-E composite tested by the 3 PB test and the PLA-X with both tests, there was a sudden failure. This result would appear to indicate a better interaction between the E-fiber and the matrix due to the sizing. This observation was enabled by the low interphase strain rate.

The maximum stress for the PLA-X and PLA-E composites was higher than for the pure PLA, (Table 4). In both the ESC and the 3 PB tests, the differences between materials were close to $30 \mathrm{MPa}$. Moreover, composite strain at break was the same whichever the test.

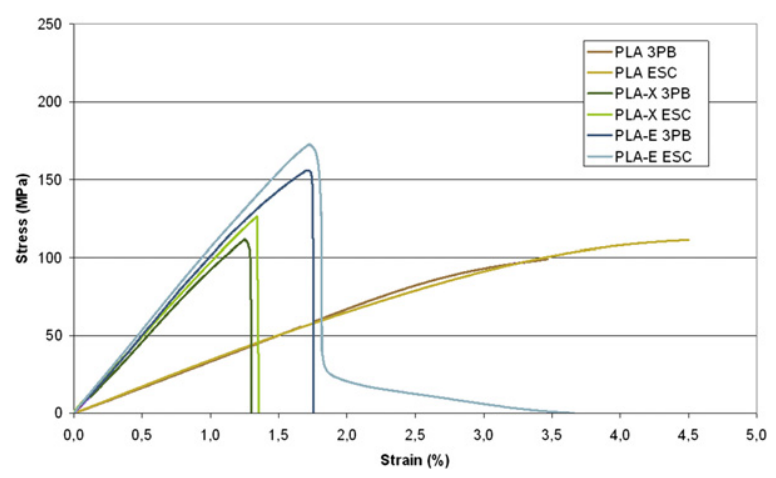

Fig. 4. Graphs of stress/strain for ESC and 3 PB tests after water ageing
The values obtained using the ESC test were higher and standard deviations lower than with the 3 PB test. These differences could be explained by the slower strain rate in the ESC test, enabling the material to reconfigure/relax [19]. During the mechanical test, it is well known that reorganization of macromolecules may occur within the polymer matrix and/or the glass fiber sizing that could be emphasized by a very slow strain rate.

Significant differences between the failure modes of the composite materials could, therefore, be revealed through the ESC test compared to the classical 3 PB test because of the low strain rate.

\section{Comparison between biocomposites}

\section{1. structure of biocomposites}

Concerning glass fiber length in composites, results show that $T_{n}$ is about $245 \mu \mathrm{m}$ for PLA-X $\left(D_{f}=0.15\right)$ and $225 \mu \mathrm{m}$ for PLA-E $\left(D_{f}=0.14\right)$. Therefore, this parameter would not influence the following results.

From DSC analysis, (Table 2) a difference in the chain structure of the composite was detected. The crystallinity of PLA-X was twice that of PLA-E which implies a modification in chain structure. Two hypotheses could explain this phenomenon. The first is that the X-glass surface is rougher than that of the E-glass, affecting the matrix chain structure. Roughness provides nucleation points on the PLA chains, explaining the higher crystallinity of the PLA-X. The second hypothesis is the migration into the sizing of alkaline glass components, which crystallize during drying. These crystals could also act as nucleation sites in the PLA matrix.

\subsection{Before water ageing}

In both the ESC and the $3 \mathrm{~PB}$ tests, flexural modulus increased in the presence of glass fibers from 3.2 GPa (pure PLA) to $10 \mathrm{GPa}$ and $10.8 \mathrm{GPa}$ (PLA-X and PLA-E 
Table 4

Comparison of mechanical properties obtained by ESC test and 3 PB test (Water).

\begin{tabular}{|c|c|c|c|c|c|c|}
\hline \multirow[t]{2}{*}{ Test material } & \multicolumn{3}{|l|}{ ESC test } & \multicolumn{3}{|l|}{3 PB Test } \\
\hline & Modulus (GPa) & Maximum stress (MPa) & Strain at break (\%) & Modulus (GPa) & Maximum stress (MPa) & Strain at break (\%) \\
\hline PLA & $3.48 \pm 0.09$ & $113 \pm 3$ & $>4.5$ & $3.26 \pm 0.05$ & $98 \pm 3$ & $3.43 \pm 0.10$ \\
\hline PLA-X & $9.83 \pm 0.00$ & $131 \pm 0$ & $1.33 \pm 0.00$ & $9.03 \pm 0.14$ & $113 \pm 7$ & $1.35 \pm 0.10$ \\
\hline PLA-E & $10.51 \pm 0.11$ & $178 \pm 1$ & $1.74 \pm 0.02$ & $10.14 \pm 1.62$ & $157 \pm 3$ & $1.72 \pm 0.05$ \\
\hline
\end{tabular}

respectively), demonstrating an increase in material rigidity induced by the fibers. The maximum stress increased from $119 \mathrm{MPa}$ for the pure matrix to $182.3 \mathrm{MPa}$ for PLA-X and 240.6 MPa for PLA-E. Moreover, the strain at break of the composites was half that of the PLA. It should be noted here that strain at break for the PLA was higher than $4.5 \%$ (maximum deflection of $12 \mathrm{~mm}$ ).

Before ageing, the X-glass fiber provided lower reinforcement than E-glass fiber. This result may be the consequence of a more brittle glass and/or a lower level of interaction at the fiber/matrix interface.

The fracture surfaces were observed by ESEM. The images obtained are presented in Fig. 5, enabling compressive and tensile zones to be defined.

In the compressive area, the same morphology was observed whichever the test used. Nevertheless, it can be noted that more sizing remained on the surface of the Xfibers than the E-fibers. The low strain rate enabled the macromolecules in the sizing to reorganize concomitantly with the relaxation of the matrix.

In the ESC test, there were slight differences between the materials in the tensile zone. ESEM observation revealed some differences between the broken sections obtained after the 3 PB and ESC tests. After the 3 PB test, matrices were disturbed by the fiber displacement in the PLA. This modification was much less visible in the composites tested by ESC. To explain these differences, it could be assumed that the higher strain rate in the 3 PB test prevented reorganization of the polymer chain around the fiber. On the contrary, the low strain rate of the ESC test enabled the matrix to creep around the displaced fiber.

\subsection{Water ageing}

\subsubsection{ESC test in water}

The mechanical property representative of short times is the Young's modulus (from 0.13 to $0.67 \mathrm{~mm}$ ). There were no major differences in modulus between the ESC and $3 \mathrm{~PB}$ tests. For the pure PLA, the modulus was 3.48 and $3.26 \mathrm{GPa}$ according to the ESC and $3 \mathrm{~PB}$ tests respectively. The values for the composites were also very close. It could be noted that the ESC values were slightly higher than those obtained in the 3 PB test but the standard deviation was lower. The maximum stress increased from the pure PLA to the PLA-X and the PLA-E. In both the ESC and the 3 PB tests, the differences between the materials were close to $30 \mathrm{MPa}$. Interestingly, the composite strains were the same in both the ESC and the 3 PB test.

The PLA modulus results showed no significant difference before and after ageing (3.20 GPa and 3.48 GPa respectively). This is due to an induction period [24] during which the water diffusion through the PLA matrix was very low. In the case of the composites, on the other hand, a slight decrease in the modulus was observed. This effect can be attributed to water diffusion at the interphase [30]. It has been well established that these regions probably have a diffusion coefficient higher than that of the bulk matrix, creating a preferential diffusion path for water molecules.

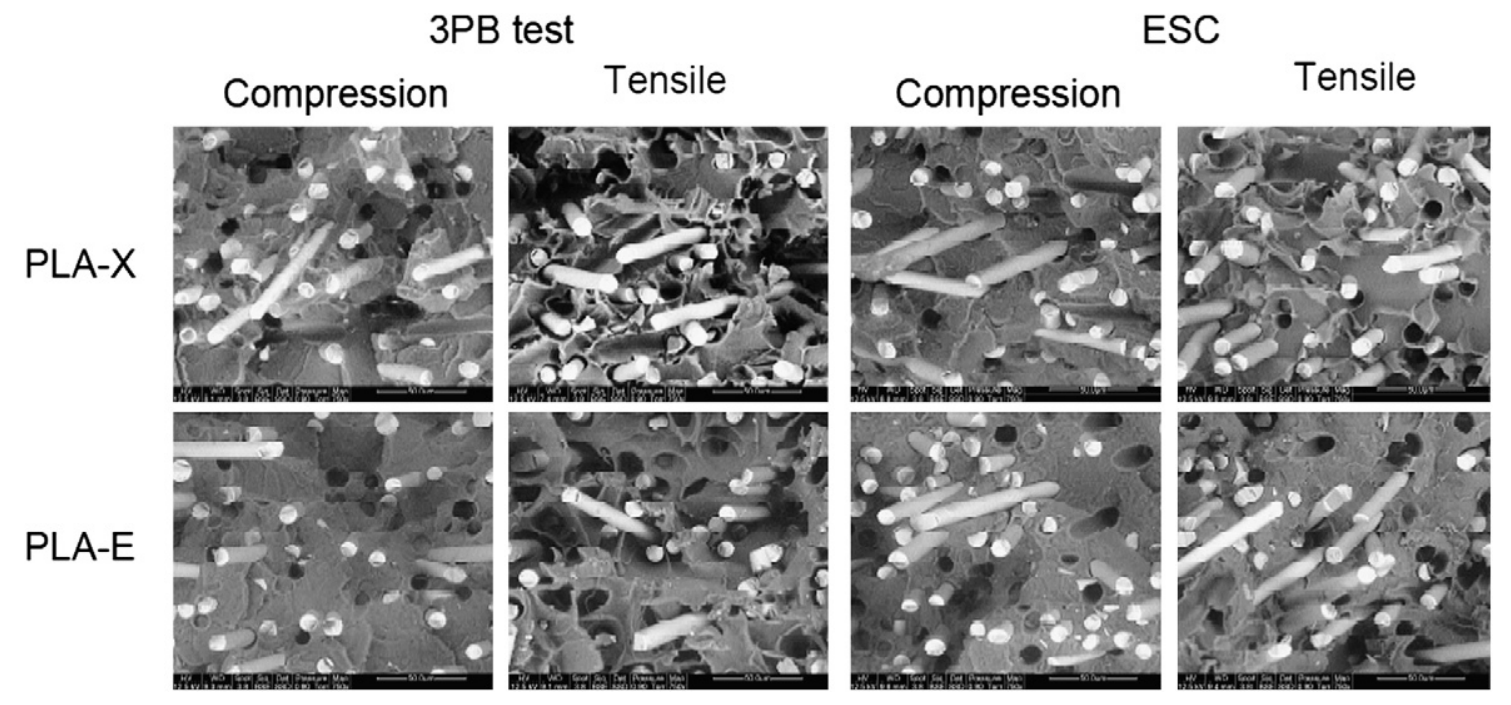

Fig. 5. Fibers and sizing after $3 \mathrm{~PB}$ test and ESC test before ageing for PLA-E and PLA-X. 

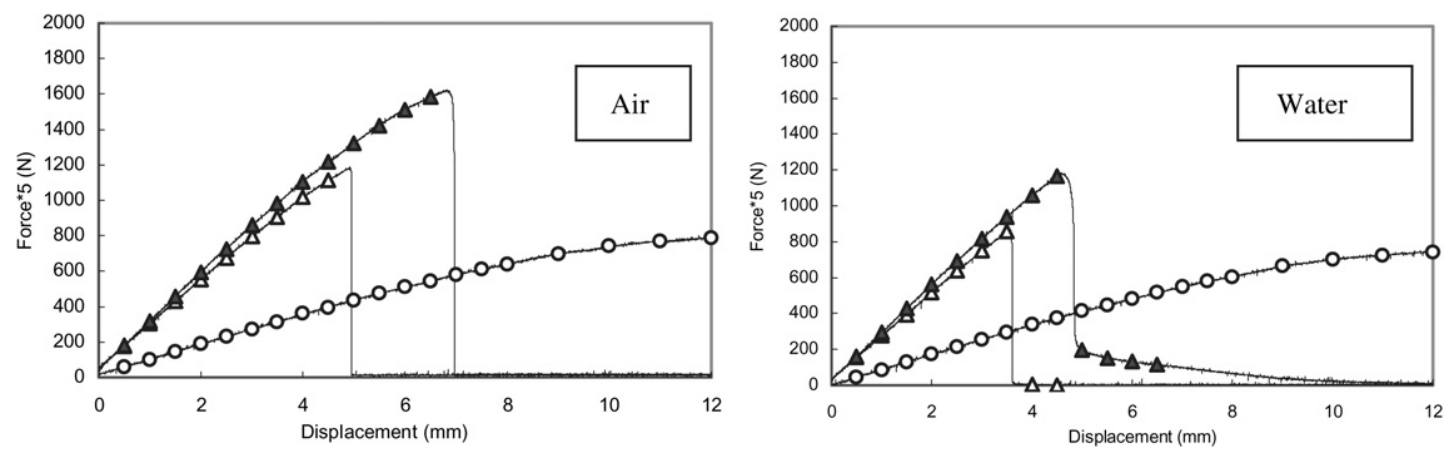

Fig. 6. Effects of water on mechanical behavior ( $\boldsymbol{\Delta}$, E-glass; $\Delta$ X-glass; O PLA).

During the ESC test (Fig. 6), the PLA was plasticized. After $24 \mathrm{~h}$ the maximum stress was lower than before ageing. These results reflect the increase of residual stress introduced by immersion [22]. By contrast, the composite was more degraded. The interphase degradation was confirmed by the earlier occurrence of the failure than before ageing. This could be due to the water molecules preferentially diffusing at the interphase and degrading the chemical "matrix/fiber" bonds. This phenomenon causes decohesion and a reduction in mechanical properties. The cracking behavior was different before and after ageing for the PLA-E. It was not as clear as for the PLA-X and was progressive due to the nature of the fibers.

During the ESC test, the materials were under mechanical strain simultaneously with water ageing, whereas the material underwent ageing before the 3 PB test.

\subsubsection{PB test after one-week's immersion in water}

Materials tested using the 3 PB test after one-week's immersion exhibited a decrease in maximum force compared to unaged materials. The Young's modulus decreased due to matrix plasticization.

Water absorption was $0.48 \%$ for the PLA matrix. By subtracting this value from the values for PLA-X and PLA-E, it is possible to measure the contribution of the fiber and the sizing. Since the X-and E-glasses have the same sizing, the difference between them can be attributed to the nature of the fiber. The X-glass fiber, which can be degraded by water, exhibited a water adsorption $25 \%$ higher than that of the E-glass. Camino et al. [31] reported that water diffusion is affected by the partial dissolution of glass fiber, which forms a number of new electrolytes.

However, the behavior difference observed before and after ageing was lower when the materials were subjected to the 3 PB test (one week) compared to the ESC (one day).

For the material tested by ESC, the maximum stress was lower in water (Table 4). This phenomenon can be explained by matrix plasticization. The water molecules were interspersed between the polymer chains, reducing the intermolecular interactions [19]. As the water absorption increased, the PLA matrix became softer, as indicated by the decrease in the modulus. Nevertheless, water plasticization had more impact on the maximum stress than on the modulus. This phenomenon can be explained by the difference in water absorption during the initial and longer-term ageing times.

Fig. 7 shows the fracture surface of the PLA-E and PLA-X as a function of the type of ageing and the area observed (compressive or tensile). In the compressive zone, the

\section{PB test}

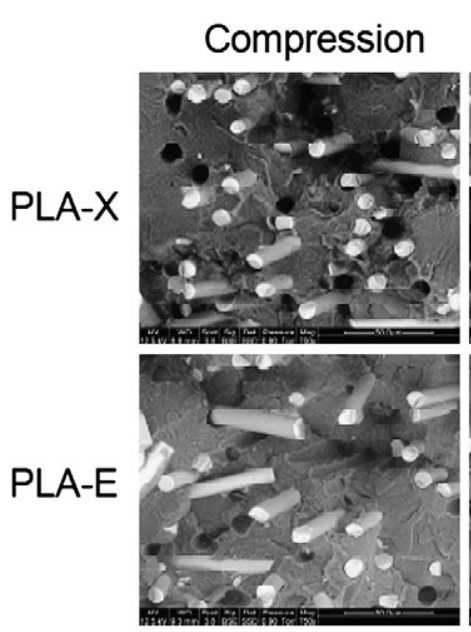

Tensile
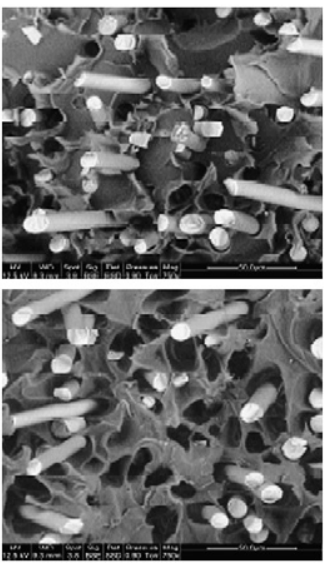

ESC

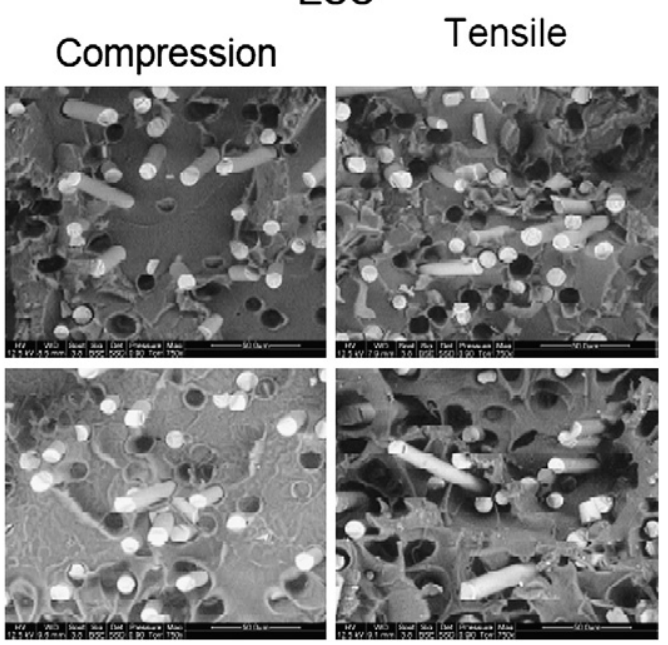

Fig. 7. Fibers and sizing after 3 PB test and ESC test after ageing for PLA-E and PLA-X 
matrix/fiber fracture seems to be similar. In both composites, the sizing had good interaction with the fiber. In the tensile zone, the surface exhibited an interfacial area with a degree of disorganization in all cases. This disorganization was more pronounced in the PLA-E. The matrix elongation was more significant after the 3 PB test than the ESC test. However, the differences were smaller and a matrix displacement occurred after the ESC test. This displacement could be connected to matrix plasticization. A swelling of the matrix was detected near the fibers. This may be due to greater water diffusion at the interface than in bulk PLA.

\section{Conclusions}

The ESC test clearly demonstrated its efficiency for studying the mechanical properties of materials in a controlled environment. Its high levels of accuracy enabled the use of only three specimens and several phenomena were revealed.

In comparison with a classical $3 \mathrm{~PB}$ test in air, the ESC test was remarkable for its ability to determine the material behavior under strain and in-service conditions as a function of the matrix, fiber and sizing used. Differences in mechanical properties were emphasized. This can particularly be explained by higher deformation of the interphase with the lower strain rate of the ESC test.

Applying a low strain rate in a water environment enabled various kinds of failure to be detected in both composites. The test was long enough to enable both bulk and interphase water diffusion, together with relaxation. The differences in cracking behavior can be ascribed to matrix/fiber interaction in relation with sizing efficiency. In the PLA-E, the composite sizing especially developed for this matrix/fiber system created good adhesion. In the PLA$\mathrm{X}$ composite, the lower mechanical properties would suggest that adhesion was lower despite the presence of sizing detected by ESEM.

The influence of water was demonstrated by the interphase swelling (ESEM observations) and the matrix softening (mechanical properties) during the ESC test. An increase in water diffusion, measured by weighing the specimens, seems to be caused by the mechanical straining of the material in the testing environment.

\section{Acknowledgments}

The authors would like to acknowledge ADEME (French Agency of Environment and Waste Management) and ANR (French National Research Agency) for their financial support. The authors are also gratefully indebted to Matériau Ingénierie Co. (Saint-Christol-lez-Alès, France) and OCV Reinforcement International Co. (Chambéry, France).

\section{References}

[1] D.R. Witze, Introduction to properties, engineering, and prospects of polylactide polymer, Ph. D. thesis, Chemical Engineering, Michingan State University, 1997.

[2] S. Li, S.P. McCarthy, Further investigations on the hydrolytic degradation of poly(DL-lactide), Biomaterials 20 (1) (1999) 35-44.

[3] E. Drumright, P.R. Gruber, D.E. Henton, Polylactic acid technology, Advanced Materials 12 (13) (2000) 1841-1846.
[4] B. Singh, N. Sharma, Mechanistic implications of plastic degradation, Polymer Degradation and Stability 93 (2008) 561-584.

[5] M. Day, K. Shaw, D. Cooney, J. Watts, B. Harrigan, Degradable polymers: the role of the degradation environment, Journal of Environment Polymer Degradation 5 (3) (1997) 137-151.

[6] G.C. Marks, G. Butters, Techniques for predicting the weathering performance of rigid PVC, Journal of Macromolecular Science A12 (1978) 569-586.

[7] H.M. Quackenbos, S.H. Samuels, Applied Polymer Symposium 4 (1967) 155.

[8] A. Davis, D. Sims, Weathering of polymers, Applied Science (1983).

[9] F. Gugumus, in: Symposium on Polymer Stabilization and Degradation: Problems, Techniques and Applications (1985) (Manchester).

[10] D. Kockott, Natural and artificial weathering of polymers, Polymer Degradation and Stability 25 (2-4) (1989) 181-208.

[11] R.P. Brown, Survey of status of test methods for accelerated durability testing, Polymer Testing 10 (1991) 3-30.

[12] J.R. White, A. Turnbull, Weathering of polymers: mechanisms of degradation and stabilization, testing strategies and modeling, Journal of Materials Science 29 (2004) 584-613.

[13] ASTM D4674-89: Standard Test Method for Accelerated Testing for Color Stability of Plastics Exposed to Indoor Fluorescent Lighting and Window-filtered Daylight. ASTM International, 1989.

[14] BS 3900 Paints: Parts F3, F5 Resistance to artificial weathering British Standards Publications (British Standards Institution, London).

[15] R.J. Martinovich, G.R. Hill, Applied Polymer Symposium 141 (1967).

[16] M.G. Wizgoski, C.H. Jacques, Stress cracking of plastics by gasoline and gasoline components, Polymer Engineering and Science 17 (1977) 854-860.

[17] H.T. Wang, B.R. Pan, Q.G. Du, Y.Q. Li, The strain in the test environmental stress cracking of plastics, Polymer Testing 22 (2003) $125-128$.

[18] J.C. Arnold, The effects of physical aging on the brittle fracture behavior of polymers, Polymer Engineering and Science 35 (1995) 165-169.

[19] J.C. Arnold, The influence of liquid uptake on environmental stress cracking of glassy polymers, Materials Science and Engineering A197 (1995) 119-124.

[20] C.T. Kelly, Li Ting, J.R. White, Slow strain-rate testing of polymers with ultraviolet exposure, Journal of Materials Science 32 (1997) 851-861.

[21] A. Turnbull, A.S. Maxwell, S. Pillai, Comparative assessment of slow strain rate, 4-pt bend and constant load test methods for measuring environment stress cracking of polymers, Polymer Testing 19 (2000) 117-129.

[22] A.S. Maxwell, A. Turnbull, Chemical probe technique for assessing the susceptibility of polymeric mouldings to environment stress cracking, Polymer Testing 22 (2003) 259-265.

[23] D.C. Wright, K.V. Gotham, Solvent-crazing criteria, Polymer Engineering and Science 23 (1983) 135-139.

[24] M.C. Hough, D.C. Wright, Two new test methods for assessing environmental stress cracking of amorphous thermoplastics, Polymer Testing 15 (1995) 407-421.

[25] E.W. Fischer, H.J. Sterzel, G. Wegner, Investigation of the structure of solution grown crystals of polylactide copolymers by means of chemical rESCtion, Kolloid ZZ Polymers 251 (1973) 980-990.

[26] G.L. Siparsky, K.J. Voorhees, J.R. Dorgan, K. Schilling, Water transport in polylactic acid (PLA), PLA/polycaprolactone copolymers, and PLA/ polyethylene glycol blends, Journal of Environmental Polymer Degradation 5 (3) (1997) 125-136.

[27] F. Henry, L.C. Costa, M. Devassine, The evolution of poly (lactic acid) degradability by dielectric spectroscopy measurements, European Polymer Journal 41 (2005) 2122-2126.

[28] M.P. Foulc, A. Bergeret, L. Ferry, P. Ienny, A. Crespy, Study of hydrothermal ageing of glass fibre reinforced PET composites, Polymer Degradation and Stability 89 (2005) 461-470.

[29] A. Bergeret, L. Ferry, P. Ienny, Vieillissement hygrométrique des composites thermoplastiques renforcés par des fibres de verre. Partie I. Les mécanismes de vieillissement un composite polyéthylène téréphtalique (PET)/verre, Revue des composites et des matériaux avancés 18 (2008) 17-31.

[30] C.J. Tsenoglou, S. Pavlidou, C.D. Papaspyrides, Evaluation of interfacial relaxation due to water absorption in fiber-polymers composites, Composites Science and Technology 66 (2006) 28552864.

[31] G. Camino, M.P. Luda, A.Ya. Polishchuk, M. Revellino, R. Blancon, G. Merlec, et al., Kinetic aspects of water sorption in polyester resin/glass-fibre composites, Composites Science and Technology 57 (1997) 1469-1482. 